\title{
JUAN RAMÓN JIMÉNEZ Y EL LEGADO DE LA MODERNIDAD
}

\author{
Juan José LANZ
}

(Barcelona: Anthropos, 2017, 270 págs.)

Es Juan Ramón Jiménez uno de los escritores y poetas que más bibliografía crítica acumula; pero como los más grandes de las letras universales, su universo literario es inagotable, como demuestra el estudio de Juan José Lanz titulado Juan Ramón Jiménez y el legado de la modernidad. El autor aclara en el prólogo el origen y circunstancias de su libro: una reunión de trabajos sobre la obra juanramoniana elaborados en los últimos quince años y que ofrecen "una visión global de las principales facetas de la obra del moguereño", con metodología afín, es decir, "con planteamiento analítico semejante y una atención simultanea al texto literario, a su hermenéutica y al diálogo que este establece con la historia literaria y general del momento" (pág. 5), y con la finalidad que explicita el título del libro: "subrayar la vinculación de la obra de Juan Ramón Jiménez con la Modernidad literaria occidental". Tales son las premisas de entendimiento del estudio de Lanz, que comprende análisis, interpretación e historia como ámbitos interdependientes que el autor sintetiza en el sintagma "metodología histórico-crítica".

Consta el libro de Juan José Lanz de siete capítulos más un apéndice y una bibliografía que se puede calificar de exhaustiva (doce páginas) y necesaria. "El legado poético de Juan Ramón Jiménez y la Modernidad" es el título del capítulo primero, tan denso de pensamiento que no resulta fácil sintetizarlo mínimamente. Parte Lanz de una clara evolución en la manera juanramoniana de entender y practicar la creación poética, aceptando que en torno a 1916, cuando escribe Diario de un poeta recién casado, se 
produce en ella un cambio profundo. En una primera etapa "sensitiva" trata el poeta de captar el instante fugaz, la impresión momentánea, el matiz cambiante, consciente, sin embargo, del fracaso de la palabra poética para «eternizar el instante fugaz», de expresar lo inefable. Con Estio (1916) y Sonetos espirituales (1917) empieza el giro de la obra juanramoniana hacia la "poesía desnuda", que se consolida en el citado Diario de un poeta recién casado (1917). Lanz resume el camino recorrido como "un periplo que parte de la inocencia para arribar a la conciencia", entendiendo que "desnudez" (que implica pureza) y "totalidad" (pensamiento abarcador e integrador) son los conceptos clave en la poesía del moguereño en esta etapa. El giro es radical en algún sentido: de la palabra insuficiente a "una fe absoluta en la palabra", que es la que crea la realidad y asegura la permanencia de lo nombrado. La palabra poética goza ahora de una virtud "creativo-cognoscitiva" evidente. Lanz pone de relieve la importancia que cobra en el poeta de Moguer la meditación sobre la Obra y sobre el papel del propio creador, identificado con Dios en el acto de creación. De igual modo señala cómo la concepción juanramoniana no es algo aislado, sino afín al pensamiento heideggeriano por un lado ("la esencia del ser no se revela en el leguaje, sino que es en él”, resume Lanz) y con el orteguiano por otro, en cuanto que la reflexión metapoética sobre el leguaje ("el ser es en el lenguaje") implica una meditación sobre el ser. Esta es la "dimensión creativo-cognoscitiva del lenguaje poético", que asienta la aspiración juanramoniana a la "totalidad" de la Obra, percibida como "unidad", y todo ello sustentado por el crítico no en supuestos meramente teóricos, sino en los textos del poeta.

El tercer tiempo poético de Juan Ramón Jiménez es el del exilio, época "suficiente" o "verdadera", en la que asume un influjo eliotiano y las doctrinas científicas einsteinianas, y donde los títulos Espacio y Tiempo son muestra explicita de ello. Tras diversas consideraciones, Lanz manifiesta algo muy interesante en relación con la circunstancia histórica del exilio, y es que "intentando su poesía expresar una independencia de las circunstancias adversas en que vive, acaba, paradójicamente, siendo consecuencia directa de ellas" (pág. 29). Lanz se detiene en lo que supone el rasgo acaso más característico de este momento: la fusión espaciotemporal en el texto, de modo que "si tiempo y espacio se funden en una unidad en la conciencia individual, y el espacio del exilio remite al de la patria, a la vez que el tiempo presente se funde con el pasado, no es extraño 
que el proceso de escritura se manifieste como un modo de reescritura, cuyo resultado más notable será el poema 'revivido', 're-creado' en su sentido más radical, tal como aparecerá en el proyecto de Leyenda" (págs. 30-31). Lo vivido y lo escrito acaban identificados: "en consecuencia, muchos de los espacios evocados desde el exilio remiten tanto a la vida escrita como a la escritura vivida" (pág. 31).

Lanz nos muestra en su investigación la evolución coherente de la lírica juanramoniana y no aislada del entorno, sino al pie de las circunstancias vitales e históricas, así como de la poesía y el pensamiento filosófico de su tiempo, algo que se muestra, por cierto, desde los primeros escritos del poeta, como delata el capítulo segundo del libro de Lanz, titulado "Intimidad y discurso en la poesía primera de Juan Ramón Jiménez", y en el cual, el poeta de Rimas (1902) se inscribe en el amplio movimiento hacia "una dimensión interior del modernismo" en el que participaban los Machado y el propio Rubén Darío, una orientación hacia la intimidad. Rimas, Arias tristes (1903), Jardines lejanos (1904) y Pastorales (1911, pero escrito en 1905) ejemplifican ese giro, dentro de un ámbito simbolista y como construcción de la intimidad en una "dimensión dialógica", "como diálogo implícito entre el yo y la conciencia objetivada", entendiendo que el concepto de "conciencia" va variando a lo largo de la obra juanramoniana. En Rimas empieza a aparecer "la conformación de una intimidad como diálogo incipiente con los elementos de una naturaleza" que pronto se codifica "en un tópico netamente modernista-simbolista como el viejo jardín, que es la vez el jardín de alma" (pág. 49), "espacios temporalizados en que el yo se reconoce en un diálogo implícito consigo mismo" (pág. 49). Esta idea la desarrolla Lanz y la enriquece con el análisis de los poemarios que siguen a Rimas, examinando los desdoblamientos del sujeto y diferentes formas de duplicidades espacio-temporales, hasta abocar a la conclusión de que "la intimidad solo puede ser construida textualmente como ficción" y que el poema es "el espacio en que se representa la construcción de una intimidad dramatizada", y donde lo íntimo lucha por exteriorizarse verbalmente en un diálogo implícito entre el yo y el otro yo en forma de "tú", "él" o "ello". Creo que con lo dicho se puede percibir la difícil síntesis de las ricas formulaciones del crítico, que en el capítulo tercero aborda el tema de "Platero y yo y la pedagogía estética nacional", un capítulo modélico, con una visión ajustada de un texto que ha sido interpretado de modos muy alejados de lo que fue y representa: el resultado de "un complejo 
proyecto de pedagogía nacional dentro de la voluntad reformista que surge del regeneracionismo finisecular, del krausismo y de la Institución Libre de Enseñanza", en consonancia con la preocupaciones pedagógicas mostradas por entonces en obras de Unamuno, Machado, Baroja, Azorín y Ortega, entre otros. Todo ello lo estudia detenidamente Lanz en relación con la escritura de Platero en las especiales circunstancias vitales de Juan Ramón y a partir de 1906, subrayando como rasgos caracterizadores la búsqueda de un ideal de belleza absoluta, con dimensión religiosa, la concepción de la poesía como instrumento de regeneración personal y nacional y el descubrimiento del folclore y lo popular desde una actitud culta y aristocrática; son aspectos que Lanz analiza junto a otros que los complementan, como el lugar central que la infancia ocupa en Platero y yo, como objeto de la pedagogía nacional y como historia lírica de su niñez (elegía), proyectada hacia el futuro (utopía); la "razón narrativa" que supera el lirismo juanramoniano; la contemplación activa y el cuestionamiento genérico que le hace ver el texto juanramoniano "más que un conjunto de poemas en rosa, quizás como relato poético" sin el cual no se explicaría la escritura de Vispera del gozo, de Salinas, y Ocnos, de Cernuda.

El capítulo cuarto de Juan Ramón Jiménez y el legado de la modernidad, discurre en torno al libro Belleza y la segunda época poética del moguereño. Se pregunta el crítico por el silencio que siguió a la publicación del mencionado poemario Belleza en 1923, hasta su nuevo libro La estación total con las Canciones de la nueva luz (1946), siendo así que los años anteriores a 1923 habían sido muy fructíferos; se centra después en la segunda época del poeta, que si se inicia con Diario de un poeta recién casado, sus prolegómenos pueden rastrearse en los libros inmediatamente anteriores, como Estio y Sonetos espirituales; es la etapa en la que se integrarían los poemas recogidos en Belleza, la fase de la "poesía desnuda" y del "verso libre", con el abandono de las formas cerradas y la reelaboración de los esquemas de la canción tradicional. Poesía desnuda supone depuración formal para expresar solo la idea neta. Juan José Lanz se extiende después sobre la noción de "pureza" en Jiménez para indagar en el proceso de interiorización y esencialización que se produce en el leguaje. El ser es en el lenguaje. Pero en su aspiración "a la expresión esencial de lo inefable" aboca al silencio. Alude también Lanz al hecho de que nombrar no es solo crear, sino, a la vez, conocer. Es la "dimensión creativo-cognoscitiva del lenguaje poético", formulando 
Juan Ramón Jiménez su aspiración a la "Totalidad" y a la "Unidad" de la Obra. Todo ello explica el proceso de depuración, corrección continua y reordenación a que someterá sus poemas en la construcción de la obra. Parca síntesis es esta de la densidad interpretativa de Lanz, que desarrolla después diferentes aspectos referidos a la organización de Belleza y, entre otras consideraciones, la referida a la célebre y polémica dedicatoria que precede a los poemas, "A la minoría siempre".

Sobre los Romances de Coral Gables (1948) y la poesía del primer exilio versa el capítulo $\mathrm{V}$ de la obra de Lanz, el cual se extiende de inicio en el relato de las condiciones y escenarios del exilio de Juan Ramón Jiménez y su esposa Zenobia, dado que "las nuevas circunstancias vitales infligen una radical transformación tanto en su carácter como en su escritura, de la que va a dejar testimonio poético en los Romances de Coral Gables, primero de los libros que publica con poemas escritos en el exilio" (pág. 145) y sobre el cual, en concreto el tratamiento del espacio y el tiempo, se detiene Lanz, haciendo ver que el espacio aparece en el poeta fuertemente temporalizado, fundiéndose en el fluir individual de la conciencia. De la agudización temporal brota el sentimiento de nostalgia. Como señala Lanz, los deícticos expresan tales sentimientos: "aquí indica el presente existencial del exilio, mientras que allí se une a la esecialidad perdida en el Moguer revivido o en la patria evocada" (pág. 153). Este proceso en el que el espacio del exilio remite al de la patria y el presente se funde con el pasado, explica que la escritura se manifieste como reescritura cuyo sentido más radical fue -ya se indicó-Leyenda, publicado tras la muerte del poeta, concretamente en 1978. Lanz expone, además, las circunstancias editoriales y de escritura de los Romances, cuestiones referente a la unidad del poemario, a la métrica y a la expresión.

Capítulo muy interesante, afín a muchas de las ideas expuestas en capítulos anteriores, es el titulado "Juan Ramón Jiménez y Albert Einstein: a vueltas con el cronotopo en Espacio y Tiempo". Parte Lanz de las coincidencias biográficas entre el sabio y el poeta, así como de las afinidades en la concepción del espacio-tiempo fundadas en el nuevo paradigma instaurado por el físico alemán. La unión de espacio y tiempo ha dado en llamarse cronotopo (Minkowski, Bajtin); tal unión o fusión se constata, como Lanz expone, en la poesía del Juan Ramón Jiménez del exilio: un espacio temporalizado y una memoria espacializada encarnados, sobre todo, en los poemarios Espacio y Tiempo. Son aspectos, por otro 
lado, en los que Lanz ha abundado a lo lago de los diferentes capítulos.

El capítulo final de la investigación de Lanz trata de "Juan Ramón Jiménez y la poesía española de posguerra (1939-1960)". Y aunque el autor indica que son notas de aproximación, no conozco otro trabajo con tal profusión de datos, fruto de la sabiduría del crítico, que abarca las influencias, presencias, afinidades, huellas, reminiscencias o como quiera llamárselas del poeta de Moguer en el período acotado. El capítulo es muy atractivo, pues demuestra, frente a incomprensiones y polémicas, la voluntad del poeta exiliado de tener presencia en las publicaciones de España, una presencia que Lanz aprecia repasando las diferentes revistas que van apareciendo en la inmediata posguerra (Corcel, Proel, Espadaña, Ínsula, La Isla de los Ratones...), así como en décadas posteriores (Caracola, Platero...) y en la obra de determinados poetas, mostrando palpablemente cómo la huella juanramoniana es poderosa y constante, individualizada y diferenciada en cada poeta, trátese de Celaya, Blas de Otero, Hierro o los grandes poetas del 50, como Ángel González, Caballero Bonald, Brines y Gamoneda. Como escribe Lanz, tras rastrear con acierto todo tipo de huellas juanramonianas, "su obra dibuja la pauta sobre la que se va a escribir una parte importante de la poesía de posguerra” (pág. 190).

A las indagaciones indicadas, se añade -como se indicó al comienzo de la reseña- un apéndice al que sigue la bibliografía que califiqué de exhaustiva. En el apéndice comenta el crítico trece poemas, ocho de Belleza y cinco de Romances de Coral Gables. Se completa así un texto crítico que agrega al conocimiento de la obra juanramoniana nuevas dimensiones críticas que han quedado especificadas a lo lago de la reseña.

José Enrique Martínez

Universidad de León 